\title{
PENGARUH KEPERCAYAAN KONSUMEN, KUALITAS PRODUK DAN PERSEPSI HARGA TERHADAP KEPUTUSAN PEMBELIAN DI FLAMINGGO COLLECTION
}

\author{
Azalia Calvina Octavia \\ Fakultas Ekonomi dan Bisnis, Program Studi Manajemen, \\ Universitas Pembangunan Nasional "Veteran", Jawa Timur \\ Email: oktavazalia@gmail.com
}

\begin{abstract}
Abstact : The purpose of this study is to determine the effect of consumer trust, product quality, and price perceptions on purchasing decisions at the Flaminggo Collection. The Analysis technique of this research was conducted using component-based SEM method using Partial Least Square approach. The basis used for hypothesis testing on PLS is resampling with bootest strapping developed by Geisser and Stone. The variable are Consumer trust (X1), Product quality (X2), Price perception (X3), and Purchase Decision (Y). The primary data in this study was by distributing questionnaires to flaminggo collection consumers. It involved 60 respondents with aged 16-33 years. Secondary data used in this study is data obtained from Flaminggo Collection for the last 6 years (2014-2020). The results of the analysis show that Consumer Trust can play an important role in Purchasing Decisions at the Flaminggo Collection because the higher consumer trust, the higher the purchasing decision at the clothing store. Product quality can play an important role in the Flaminggo Collection because the higher the quality of the product, the higher the purchasing decision at the clothing shop. Price perception can play an important role in purchasing decisions at the Flaminggo Collection because the higher the price perception, the higher the purchasing decision at the clothing store.
\end{abstract}

Keywords: consumer trust, product quality, price perception, and purchase decision.

\section{PENDAHULUAN}

Manusia sebagai satu-satunya jenis makhluk hidup yang memiliki kebutuhan lain selain kebutuhan primer (utama) dalam kehidupannya, kebutuhan lainitu adalah kebutuhan sekunder dan kebutuhan tersier. Kebutuhan sekunder akan dipenuhi setelah kebutuhan primer telah tercukupi. Kebutuhan ini tidak bersifat memaksa, namun dengan pemenuhan kebutuhan ini maka manusia akan menjadi lebih baik dan akan tetap hidup apabila tidak terpenuhi. Kebutuhan sekunder meliputi pendidikan, wisata, dan hiburan.

Kebutuhan lain yang tidak terlalu perlu dalam menentukan kelangsungan hidup yang sifatnya dibawah primer dan sekunder adalah kebutuhan tersier. Pada umumnya berupa barang yang dianggap mewah seperti mobil, perhiasan, dan peralatan elektronik. Dalam kehidupan sehari-hari, manusia selalu melakukan keputusan ekonomi untuk memilih prioritas dalam kehidupannya untuk memenuhi kebutuhan dan kebutuhan primer ini harus dipenuhi pertama, sebelum kebutuhan sekunder dan tersier. Kebutuhan primer yang mudah didapatkan dengan Cuma - cuma yaitu seperti matahari, udara, air namun untuk kebutuhan tempat tinggal dan pakaian manusia harus berusaha untuk mendapatkannya. Pakaian sebagai salah satu kebutuhan primer manusia di era modern seperti ini menjadi sesuatu hal yang sangat diperhatikan. Model berpakaian setiap orang atau biasa disebut dengan fashion di Indonesia semakin berkembang mengikuti arusmodernisasi.Dengan adanya fashion tidak menuntut kemungkinan akan menunjang penampilan seseorang dalam berpakaian lebih utamanya agar menjadi trand center di lingkungan masyarakat. Produk fashion meliputi Pakaian, tas, aksesoris, dan lain sebagainya. 
Dalam penyebaran kuesioner sebanyak 20 responden dapat dilihat 18 responden atau 90\% memberikan jawaban YA atas kepercayaan konsumen, sehingga banyak konsumen mempercayai toko tersebut sebagai waadah untuk mereka berbelanja pakaian. Pada pernyataan yang kedua terdapat 17 responden atau 85\% menyatakan YA atas produk yang berkualitas pada toko flaminggo collection. Hal ini menunjukkan bahwa konsumen memiliki anggapan produk yang dijualkan pada toko Flaminggo Collection adalah produk yang berkualitas. Selanjutnya pada pernyataan yang ketiga terdapat 16 responden atau $80 \%$ Kotler menyatakan TIDAK atas harga produk yang terbilang murah bagi konsumen dikarenakan dekat dengan Flaminggo Collection ada beberapa toko yang menjual produk sejenis dengan harga yang terbilang sangat murah dibandingkan dengan harga pada Flaminggo Collection. Salah satunya adalah Toko All items, toko tersebut menjual produk pakaian yang sejenis dengan Flaminggo Collection hanya mulai dari 35.000 saja. Tetapi kualitas produk tidak sebagus dengan kualitas produk pada Flaminggo Collection. Menurut Keller (2009:179) menyatakan bahwa yang dilakukan oleh konsumen pada saat membuat keputusan pembelian antara lain: pengenalan masalah, pencarian informasi, evaluasi alternatif, keputusan pembelian dan perilaku setelah membeli. Berdasarkan teori tersebut disimpulkan bahwa keputusan pembelian yang dilakukan berdasarkan dengan apa yang telah konsumen pertimbangkan sesuai dengan kebutuhan dan keinginan mereka. Walaupun Flaminggo Collection selalu dipenuhi dengan pengunjung. Namun, penjualan Flaminggo Collection juga mengalami penurunan di setiap tahunnya. Hal ini dapat dilihat dari tabel berikut:

Tabel 1. Data Jumlah Penjualan Flaminggo CollectionTahun 2016-2020

\begin{tabular}{|c|c|}
\hline Tahun & Jumlah Penjualan Per Tahun \\
\hline 2016 & 298.699 .000 \\
\hline 2017 & 275.000 .000 \\
\hline 2018 & 270.500 .000 \\
\hline 2019 & 281.850 .000 \\
\hline 2020 & 283.125 .000 \\
\hline
\end{tabular}

Sumber: Data Penjualan Flaminggo Collection (2016-2020)

Dapat disimpulkan dari tabel diatas omset penjualan Toko Baju Flaminggo Collection ini mengalami sedikit penurunan di tahun 2018 sebanyak Rp 5.500.000 dari tahun 2017. Hal ini yang menjadi perhatian oleh pemilik toko untuk lebih memahami keinginan konsumen agar dapat mempengaruhi keputusan pembelian sehingga, pada tahun 2019 sampai dengan tahun 2020 mengalami peningkatan yang cukup baik. Mengingat kepercayaan merupakan pengetahuan kongnitif tentang sebuah objek atau produk, sehingga memunculkan sikap yang memberikan sebuah tanggapan perasaan tentang objek atau produk. Semakin tinggi kepercayaan konsumen, maka semakin besar pula keputusan konsumen dalam membeli suatu produk.Sebaliknya, apabila kepercayaan konsumen rendah atau minim, maka semakin kecil pula kemungkinan konsumen dalam melalukan keputusan pembelian suatu produk. Faktor kepercayaan merupakan salah satu kunci dalam setiap jual beli. Bila pada pihak penjual dan pembeli tidak ada rasa saling percaya maka tidak akan terjadi transaksi.

Dari uraian diatas penelitian ini lebih memfokuskan pada faktor kepercayaan konsumen, kualitas produk, serta lokasi berpengaruh terhadap keputusan pembelian di Flaminggo Collection, sehingga berdasarkan latar belakang tersebut mengangkat topik "Pengaruh kepercayaan konsumen, kualitas produk, dan persepsi harga berpengaruh terhadap keputusan pembelian di Flaminggo Collection". 


\section{Hipotesis Penelitian}

Berdasarkan latar belakang dan kerangka pemikiran yang telah dibentuk di atas, maka dapat ditarik kesimpulan hipotesis sebagai acuan dalam penelitian ini yang didasarkan pada teori dan penelitian terdahulu. Berikut adalah hipotesis yang diajukan :

H1 : Diduga Kepercayaan Konsumen berpengaruh positif terhadap keputusan pembelian di Flaminggo Collection.

H2 : Diduga Kualitas produk berpengaruh positif terhadap keputusan pembelian di Flaminggo Collection.

H3 : Diduga Persepsi Harga berpengaruh positif terhadap keputusan pembelian di Flaminggo Collection.

\section{METODE PENELITIAN}

\section{Definisi Operasional Dan Pengukuran Variabel}

Kepercayaan Konsumen (X1)

Indikator dari variabel kepercayaan konsumen menurut(Ishak, 2011:60):

1) $\mathbf{X 1 . 1}$ = Percaya merupakan suatu keyakinan akan produk yang dipakai saat ini.

2) $\mathbf{X 1 . 2}$ = Merasa dapat mengandalkan produk untuk melayani kebutuhan dengan baik.

3) $\mathbf{X 1 . 3 ~ = ~ P r o d u k ~ d a p a t ~ m e m e n u h i ~ k e i n g i n a n ~ p e l a n g g a n ~ y a n g ~ d i a r t i k a n ~ s e m u a ~}$ produk.

\section{Kualitas Produk (X2)}

Indikator dari variabel kualitas produk menurut Tjiptono 2008 dalam Wifky Muharam dan EuisSoliha (2017):

\section{1) $\mathrm{X} 2.1$ = Performance $($ Kinerja)}

Karakteristik dimana produk tersebut mudah saat pengoperasian atau digunakan oleh konsumen.

2) X2.2 = Perceived Quality (Kesan Kualitas)

Merupakan pendapat konsumen tentang keseluruhan baiknya suatuproduk atau keunggulannya.

3) X2.3 = Conformance to specification (Kesesuaian dengan Spesifikasi)

Diartikan sebagai tingkat kesesuaian produk dengan standar yang telah ditetapkan.

\section{Persepsi Harga (X3)}

Indikator yang digunakan untuk mengukur persepsi harga diantaranya:

1) X3.1 = Kesesuaian harga dengan manfaat Harga yang ditawarkan sesuai dengan manfaat yang dirasakan oleh konsumen.

2) X3.2 = Keterjangkauan Harga Harga terjangkau oleh pengguna adalah harga yang murah sehingga dapat dibeli oleh semua orang.

3) $\mathrm{X3.2}$ = Daya saing harga

Harga yang ditawarkan kompetitif disbanding produk took baju lainnya. 


\section{Keputusan Pembelian (Y)}

Indikator dalam keputusan pembelian menurut Kotler dan Keller dalam Senggetang, Silvya, dan Sileyljeova (2019):

\section{1) Y1= Kebiasaan dalam membeli produk}

Merupakan kecenderungan konsumen untuk melakukan pembelian produk di flaminggo collection.

2) Y2= Memberikan rekomendasi kepada orang lain

Menggambarkan perilaku konsumen dimana mereka memberikan rekomendasi atau pilihan maupun saran bagi orang lain dari suatu produkyang mereka anggap mempunyai nilai bagus dan berkualitas terhadap produk di flaminggo collection.

3) Y3= Melakukan pembelian ulang

Menggambarkan perilaku seseorang yang merasa terpuaskan keinginanya dari flaminggo collection dan akan melakukan pembelian ulang karena dianggap flaminggo collection mampu memberikan apa yang diinginkan konsumen.

\section{Pengukuran Variabel}

Skala yang digunakan dalam penelitian ini adalah skala ordinal dengan teknik pembobotan likert. Menurut Riduwan (2010:84) definisi Skala Ordinal adalah Skala Ordinal adalah skala yang didasarkan pada rangking, diurutkan dari jenjang yang lebih tinggi sampai jenjang yang terendah atau sebaliknya. Menurut Sugiyono (2010:93) skala likert digunakan untuk mengukur sikap, pendapat, dan persepsi seseorang atau sekelompok orang tentang fenomena sosial. Variabel yang akan diukur dalam skala likert dijabarkan menjadi indikator variabel sebagai titik tolak ukur yang dapat berupa pertanyaan atau pernyataan. Analisis dilakukan dengan meminta penilaian responden terhadap suatu konsep tertentu, dimana setiap kategori jawaban dibuat dengan menggunakan skala 1-5.

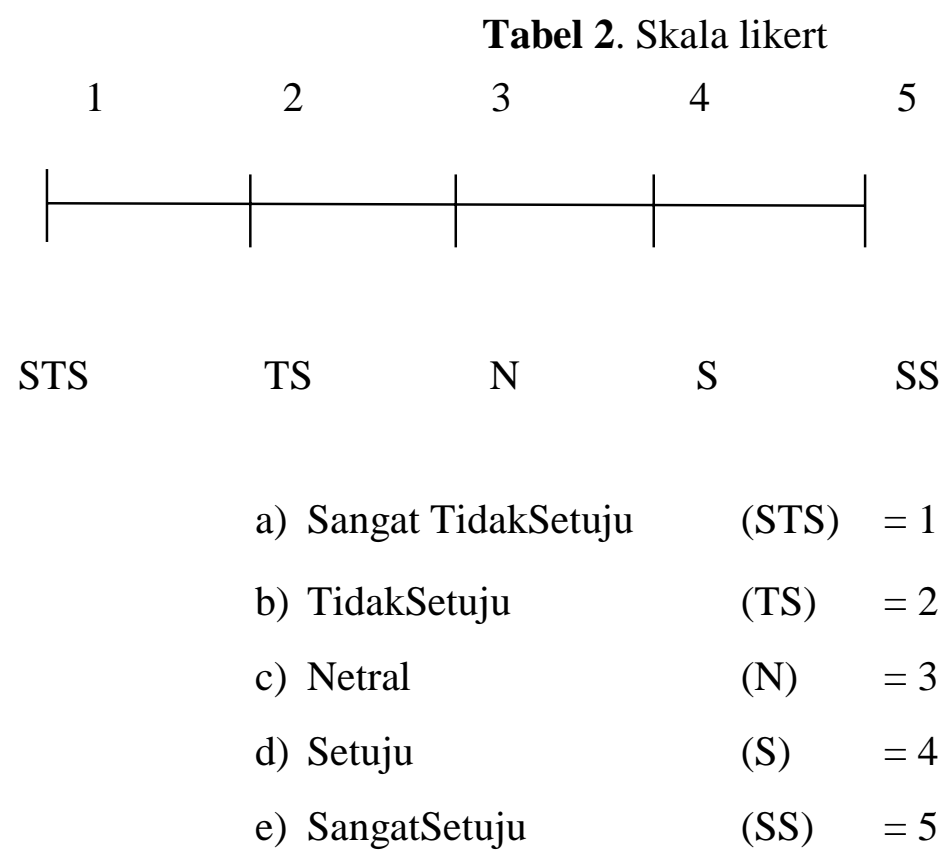




\section{Metode Analisis Data dan Uji Hipotesis Metode Analisis Data}

Analisis data dilakukan dengan menggunakan metode SEM berbasiskomponen dengan menggunakan Teknik Partial Least Square (PLS), karena perangkat ini banyak dipakai untuk analisis kausal- produktif yang rumit dan merupakan teknik yang sesuai untuk digunakan dalam aplikasi prediktif dan pengembangan teori seperti pada penelitian ini.

Cara kerja PLS estimasi parameter yang didapat dengan PLS dapat dikategorikan menjadi tiga. Kategori pertama yaitu weight estimate yang digunakan untuk menciptakan skor atau nilai variabel laten. Kedua mencerminkan estimasi jalur (path estimate) yang menghubungkan variabel laten dan antar variabel laten dan indikatornya (loading), ketiga berkaitan dengan means dan lokasi parameter (nilai konstanta regresi) untuk indikator dan variabel laten. Untuk memperoleh ketiga estimasi ini, PLS menggunakan proses literasi tiga tahap yang menghasilkan estimasi. Tahap pertama menghasilkan weight estimate,tahap kedua menghasilkan estimasi untuk inner model dan outer model, tahap ketiga menghasilkan estimasi mean dan lokasi (konstanta). Data yang digunakan dalam PLS tidak harus berdistribusi normal multivariate dan jumlah sampel tidak harus besar.(Ghozali merekomendasikan antara 30-100). Karena jumlah sampel yang digunakan dalam penelitian ini kecil (<100) maka digunakanPLS. Pengujian dengan SEM berbasiskomponen atau PLS, digunakan dengan bantuan Smart PLS. PLS mengenal dua macam komponen dalam model kausal yaitu model pengukuran (measurement models) dan model structural (structural model).

Melalui pendekatan ini, pendugaan variabel laten dalam PLS adalah sebagai exact kombinasi linear dari indikator, sehingga mampu menghindari masalah indeterminancy dan menghasilkan skor kemasan yang tepat. Pendekatan PLS didasarkan pada pergeseran analisis dari pengukuran estimasi parameter model menjadi pengukuran prediksi yang relevan. Sehingga fokus analisis bergeser dari hanya estimasi dari penafsiran signifikan parameter menjadi validitas dan akurasi prediksi. Variabel laten bisa berupa hasil pencerminan indikatornya, diistilahkan dengan indikator refleksi (reflective indicator) dan konstruk dibentuk (formatif) oleh indikatornya atau disebut indikator formatif (formative indicator).

\section{Uji Validitas Dan Reliabilitas}

Pada PLS evaluasi validitas model pengukuran atau outer model yang menggunakan indikator refleksif dievaluasi dengan convergent dan diskriminan validity. Sedangkan outer model dengan formatif indikator dievaluasi berdasaarkan pada substantive contentnya yaitu dengan membandingkan besarnya relative weight dan melihat signifikansi dari ukuran weight tersebut berdasarkan pada Chin dalam (Ghozali, 2008:24).

Convergent validity dari model pengukuran dengan reflektif indikator dinilai berdasarkan korelasi antara item score / component score dengan construct score yang dihitung dengan PLS. ukuran refleksif individual dikatakan tinggi jika berkorelasi lebih dari 0,07 dengan konstruk yang ingin diukur. Namun demikian menurut Chin (Ghozali,2008:24) untuk penelitian tahap awal dari pengembangan skala pengukuran nilai loading 0,05 sampai 0,6 dianggap cukup. Sedangkan discriminant validity dinilai berdasarkan cross loading, jika korelasi konstruk dengan item pengukuran lebih besar dari pada ukuran konstruk lainnya, maka hal ini menunjukkan bahwa konstruk laten memprediksi ukuran pada blok.Bisa juga dinilai dengan Square Root Of Average Extracted (AVE), jikanilai akar kuadrat AVE setiap konstruk lebih besar dari nilai korelasi antar konstruk dengan konstruk lainnya dalam model 
maka dikatakan memiliki nilai discriminant validity yang baik (Fornell dan Lacker dalam Ghozali:2008).

\section{HASIL DAN PEMBAHASAN}

\subsection{Hasil penelitian}

\section{Deskripsi Hasil Penelitian}

\section{Analisis Karakteristik Responden}

Data mengenai keadaan responden yang dapat diketahui melalui jawaban responden dari pernyataan - pernyataan yang telah diajukan ketika menyebar kuesioner.

Tabel 3. Karakteristik Responden berdasarkan Usia

\begin{tabular}{|c|c|c|c|}
\hline No. & Usia & Jumlah & Presentase (\%) \\
\hline 1. & $\mathbf{1 6 - 2 1}$ & $\mathbf{2 8}$ & $\mathbf{4 6 , 6 \%}$ \\
\hline 2. & $\mathbf{2 2 - 2 7}$ & 14 & $\mathbf{2 3 , 3 \%}$ \\
\hline 3. & $28-33$ & 7 & $11,7 \%$ \\
\hline 4. & $>33$ & 11 & $18,4 \%$ \\
\hline & TOTAL & 60 & $100 \%$ \\
\hline
\end{tabular}

Sumber: Data Kuesioner Diolah, 2021

Berdasarkan tabel diatas dapat dilihat bahwa responden yang berkunjung dan melakukkan pembelian di Flaminggo Collection dan mengisi kuesioner yang dibagikan sebanyak 60 responden lebih didominasi oleh responden yang berusia 16-21 tahun sebanyak 28 responden, kemudian pada peringkat kedua adalah responden yang berusia 22-27 tahun sebanyak 14 responden, kemudian pada peringkat ketiga adalah responden yang berusia 28-33 tahun sebanyak 7 responden, sedangkan sisanya pada usia $>33$ tahun sebanyak 11 responden.

Tabel 4. Karakteristik Responden Berdasarkan Pendapatan

\begin{tabular}{|c|c|c|c|}
\hline No. & Pendapatan & Jumlah & $\begin{array}{c}\text { Presentase } \\
(\mathbf{1 0 0 \% )}\end{array}$ \\
\hline 1. & $500.000-1.000 .000$ & 36 & $60 \%$ \\
\hline 2. & $>1.000 .000-5.000 .000$ & 21 & $35 \%$ \\
\hline 3. & $>5.000 .000$ & 3 & $5 \%$ \\
\hline & TOTAL & $\mathbf{6 0}$ & $\mathbf{1 0 0 \%}$ \\
\hline
\end{tabular}

Sumber: Data Diolah,2021

Berdasarkan tabel diatas dapat dilihat bahwa responden yang berkunjung dan membeli produk Flaminggo Collection dan mengisi kuesioner yang dibagikan sebanyak 60 kuesioner dari tabel diatas lebih dominan responden yang berpendapatan $500.000-1.000 .000$ sebanyak 36 responden sedangkan pendapatan $>1.000 .000-5.000 .000$ sebanyak 21 responden dan responden yang berpendapatan $>5.000 .000$ sebanyak 3 responden. 


\section{Deskripsi Data Variabel}

Kepercayaan Konsumen (X1)

Tabel 5. Frekuensi Hasil Jawaban Responden untuk Variabel X1

\begin{tabular}{|c|c|c|c|c|c|c|c|}
\hline \multirow[t]{2}{*}{ No. } & \multirow[t]{2}{*}{ Pernyataan } & \multicolumn{5}{|c|}{ Skor Jawaban } & \multirow[t]{2}{*}{ Total } \\
\hline & & 1 & 2 & 3 & 4 & 5 & \\
\hline \multirow[t]{2}{*}{1.} & \multirow{2}{*}{$\begin{array}{l}\text { Saya percaya dengan } \\
\text { Flaminggo Collection } \\
\text { sebagai wadah untuk } \\
\text { berbelanja pakaian }\end{array}$} & - & - & 2 & 15 & 43 & 60 \\
\hline & & - & - & $3,3 \%$ & $25,0 \%$ & $71,7 \%$ & $100 \%$ \\
\hline \multirow[t]{2}{*}{2.} & \multirow{2}{*}{$\begin{array}{l}\text { Saya dapat } \\
\text { mengandalkan } \\
\text { Flaminggo Collection } \\
\text { untuk mencari } \\
\text { kebutuhan fashion } \\
\text { dengan baik }\end{array}$} & - & - & 4 & 14 & 42 & 60 \\
\hline & & - & - & $6,7 \%$ & $23,3 \%$ & $70,0 \%$ & $100 \%$ \\
\hline \multirow[t]{2}{*}{3.} & \multirow{2}{*}{$\begin{array}{l}\text { Saya merasa bahwa } \\
\text { produk Flaminggo } \\
\text { Collection sesuai } \\
\text { dengan keinginan }\end{array}$} & - & - & 24 & 10 & 26 & 60 \\
\hline & & - & - & $40,0 \%$ & $16,7 \%$ & $43,3 \%$ & $100 \%$ \\
\hline
\end{tabular}

Sumber: Data Kuesioner Diolah

\section{Kualitas Produk (X2)}

Tabel 6. Frekuensi Hasil Jawaban Responden untuk variable X2

\begin{tabular}{|c|c|c|c|c|c|c|c|}
\hline \multirow{2}{*}{$\begin{array}{l}\mathbf{N} \\
\mathbf{o .}\end{array}$} & \multirow[t]{2}{*}{ Pernyataan } & \multicolumn{5}{|c|}{ Skor Jawaban } & \multirow[t]{2}{*}{ Total } \\
\hline & & 1 & 2 & 3 & 4 & 5 & \\
\hline \multirow[t]{2}{*}{1.} & \multirow{2}{*}{$\begin{array}{l}\text { Menurut Saya produk } \\
\text { Flaminggo Collection } \\
\text { nyaman saat digunakan }\end{array}$} & - & - & 6 & 11 & 43 & 60 \\
\hline & & - & - & $10,0 \%$ & $18,3 \%$ & $71,7 \%$ & $100 \%$ \\
\hline \multirow[t]{2}{*}{2.} & \multirow{2}{*}{$\begin{array}{l}\text { Menurut Saya Flaminggo } \\
\text { Collection memiliki } \\
\text { banyak variasi produk } \\
\text { yang dijual serta bahan } \\
\text { yang berkualitas daripada } \\
\text { toko lainnya }\end{array}$} & - & - & 5 & 13 & 42 & 60 \\
\hline & & - & - & $8,3 \%$ & $21,7 \%$ & $70,0 \%$ & $100 \%$ \\
\hline \multirow[t]{2}{*}{3.} & \multirow{2}{*}{$\begin{array}{l}\text { Menurut Saya produk } \\
\text { Flaminggo Collection } \\
\text { memiliki produk pakaian } \\
\text { dengan standar jahitan } \\
\text { yang rapi dan tidak } \\
\text { ditemukannya cacat pada } \\
\text { produk }\end{array}$} & - & - & 24 & 10 & 26 & 60 \\
\hline & & - & - & $40,0 \%$ & $16,7 \%$ & $43,3 \%$ & $100 \%$ \\
\hline
\end{tabular}

Sumber: Data Kuesioner Diolah 


\section{Persepsi Harga (X3)}

Tabel 7. Frekuensi Hasil Jawaban Responden untuk variable X3

\begin{tabular}{|c|c|c|c|c|c|c|c|}
\hline \multirow[t]{2}{*}{ No. } & \multirow[t]{2}{*}{ Pernyataan } & \multicolumn{5}{|c|}{ Skor Jawaban } & \multirow[t]{2}{*}{ Total } \\
\hline & & 1 & 2 & 3 & 4 & 5 & \\
\hline \multirow[t]{2}{*}{1.} & \multirow{2}{*}{$\begin{array}{l}\text { Menurut Saya } \\
\text { harga yang } \\
\text { ditawarkan sesuai } \\
\text { dengan manfaat } \\
\text { yang saya rasakan }\end{array}$} & - & - & 4 & 12 & 44 & 60 \\
\hline & & - & - & $6,7 \%$ & $20,0 \%$ & $73,3 \%$ & $100 \%$ \\
\hline \multirow[t]{2}{*}{2.} & \multirow{2}{*}{$\begin{array}{l}\text { Menurut Saya } \\
\text { Flaminggo } \\
\text { Collection } \\
\text { menjual } \\
\text { produknya dengan } \\
\text { harga yang } \\
\text { terjangkau }\end{array}$} & - & - & 44 & 7 & 9 & 60 \\
\hline & & - & - & $73,3 \%$ & $11,7 \%$ & $15,0 \%$ & $100 \%$ \\
\hline \multirow[t]{2}{*}{3.} & \multirow{2}{*}{$\begin{array}{l}\text { Menurut Saya } \\
\text { produk Flaminggo } \\
\text { Collection } \\
\text { menjual produk } \\
\text { dengan harga } \\
\text { yang murah } \\
\text { daripada toko } \\
\text { baju lainnya. }\end{array}$} & 33 & 8 & 16 & 2 & 1 & 60 \\
\hline & & $55,0 \%$ & $13,3 \%$ & $26,7 \%$ & $3,3 \%$ & $1,7 \%$ & $100 \%$ \\
\hline
\end{tabular}

Sumber: Data Kuesioner Diolah

\section{Keputusan Pembelian (Y)}

Tabel 8. Frekuensi Hasil Jawaban Responden untuk variabel Y

\begin{tabular}{|c|c|c|c|c|c|c|c|}
\hline \multirow[t]{2}{*}{ No. } & \multirow[t]{2}{*}{ Pernyataan } & \multicolumn{5}{|c|}{ Skor Jawaban } & \multirow[t]{2}{*}{ Total } \\
\hline & & 1 & 2 & 3 & 4 & 5 & \\
\hline \multirow[t]{2}{*}{1.} & \multirow{2}{*}{$\begin{array}{l}\text { Saya selalu } \\
\text { berbelanja pakaian } \\
\text { di Flaminggo } \\
\text { Collection }\end{array}$} & - & 1 & 10 & 5 & 44 & 60 \\
\hline & & - & $1,7 \%$ & $16,7 \%$ & $8,3 \%$ & $73,3 \%$ & $100 \%$ \\
\hline \multirow[t]{2}{*}{2.} & \multirow{2}{*}{$\begin{array}{l}\text { Saya selalu } \\
\text { merekomendasikan } \\
\text { Flaminggo } \\
\text { Collection kepada } \\
\text { orang-orang } \\
\text { disekeliling saya } \\
\text { sebagai shopping } \\
\text { centre untuk } \\
\text { berbelanja pakaian }\end{array}$} & - & 1 & 9 & 6 & 44 & 60 \\
\hline & & - & $1,7 \%$ & $15,0 \%$ & $10,0 \%$ & $73,3 \%$ & $100 \%$ \\
\hline \multirow[t]{2}{*}{3.} & \multirow{2}{*}{$\begin{array}{l}\text { Saya melakukkan } \\
\text { pembelian produk } \\
\text { di Flaminggo } \\
\text { Collection }\end{array}$} & - & - & 3 & 10 & 47 & 60 \\
\hline & & - & - & $5,0 \%$ & $16,7 \%$ & $78,3 \%$ & $100 \%$ \\
\hline
\end{tabular}

Sumber : Data Kuesioner Diolah 


\section{Analisis Data}

\section{1) Outer Model (Model Pengukuran dan Validitas Indikator)}

Model pengukuran dalam penelitian ini menggunakan variabel eksogen dengan indikator reflektif antara lain variabel Kepercayaan Konsumen (X1), Kualitas Produk (X2), dan Persepsi Harga (X3), serta variabel endogen yaitu Keputusan Pembelian (Y). Untuk mengukur validitas indikator salah satunya dengan didasarkan pada output tabel outer Loading, yaitu dengan melihat besarnya nilai factor loadingnya, karena dalam pemodelan ini seluruh indikator menggunakan reflektif, maka tabel yang digunakan adalah output Outer Loadings.

Tabel 9. Outer Loadings (Mean, STDEV, T-Values)

\begin{tabular}{|c|c|c|c|c|c|}
\hline & $\begin{array}{l}\text { Factor } \\
\text { Loading } \\
(\mathrm{O})\end{array}$ & $\begin{array}{l}\text { Sample } \\
\text { Mean } \\
\text { (M) }\end{array}$ & $\begin{array}{l}\text { Standard } \\
\text { Deviation } \\
(\text { STDEV) }\end{array}$ & $\begin{array}{c}\text { Standard } \\
\text { Error } \\
(\mathrm{STERR}) \\
\end{array}$ & $\begin{array}{c}\text { T Statistics } \\
(|\mathrm{O} / \mathrm{STERR}|)\end{array}$ \\
\hline $\begin{array}{c}\text { X1.1<- } \\
\text { KEPERCAYAAN } \\
\text { KONSUMEN } \\
(\mathrm{X} 1)\end{array}$ & 0.841436 & 0.844566 & 0.042043 & 0.042043 & 20.013596 \\
\hline $\begin{array}{c}\mathrm{X} 1.2<- \\
\text { KEPERCAYAAN } \\
\text { KONSUMEN } \\
\text { (X1) }\end{array}$ & 0.798054 & 0.786736 & 0.051502 & 0.051502 & 15.495696 \\
\hline $\begin{array}{c}\text { X1.3 <- } \\
\text { KEPERCAYAAN } \\
\text { KONSUMEN } \\
(\mathrm{X} 1)\end{array}$ & 0.880249 & 0.881318 & 0.022199 & 0.022199 & 39.653095 \\
\hline $\begin{array}{c}\text { X2.1 <- } \\
\text { KUALITAS } \\
\text { PRODUK }(\mathrm{X} 2) \\
\end{array}$ & 0.896345 & 0.897258 & 0.015543 & 0.015543 & 57.667786 \\
\hline $\begin{array}{c}\text { X2.2<- } \\
\text { KUALITAS } \\
\text { PRODUK (X2) } \\
\end{array}$ & 0.854709 & 0.854358 & 0.028535 & 0.028535 & 29.952965 \\
\hline $\begin{array}{c}\text { X2.3<- } \\
\text { KUALITAS } \\
\text { PRODUK (X2) } \\
\end{array}$ & 0.823577 & 0.821899 & 0.032493 & 0.032493 & 25.346286 \\
\hline $\begin{array}{c}\text { X3.1<- } \\
\text { PERSEPSI } \\
\text { HARGA (X3) } \\
\end{array}$ & 0.804077 & 0.800905 & 0.056668 & 0.056668 & 14.189377 \\
\hline $\begin{array}{c}\text { X3.2<- } \\
\text { PERSEPSI } \\
\text { HARGA (X3) } \\
\end{array}$ & 0.882747 & 0.886011 & 0.020064 & 0.020064 & 43.996720 \\
\hline $\begin{array}{c}\text { X3.3<- } \\
\text { PERSEPSI } \\
\text { HARGA (X3) }\end{array}$ & 0.778551 & 0.779781 & 0.072810 & 0.072810 & 10.692978 \\
\hline
\end{tabular}




\begin{tabular}{|c|c||c||c|c||c|}
\hline \hline $\begin{array}{c}\text { Y1 <- } \\
\text { KEPUTUSAN } \\
\text { PEMBELIAN (Y) }\end{array}$ & 0.745126 & 0.736591 & 0.062245 & 0.062245 & 11.970801 \\
\hline \hline $\begin{array}{c}\text { Y2 <- } \\
\text { KEPUTUSAN } \\
\text { PEMBELIAN (Y) }\end{array}$ & 0.901972 & 0.899711 & 0.023117 & 0.023117 & 39.018404 \\
\hline \hline $\begin{array}{c}\text { Y3 <- } \\
\text { KEPUTUSAN } \\
\text { PEMBELIAN (Y) }\end{array}$ & 0.844437 & 0.840844 & 0.037722 & 0.037722 & 22.385850 \\
\hline \hline
\end{tabular}

Dari tabel diatas, validitas indikator diukur dengan melihat Nilai Factor Loading dari variable ke indikatornya, dikatakan validitasnya mencukupi apabila lebih besar dari 0,5 dan atau nilai T-Statistic lebih besar dari 1,96 (nilai Z pada $\alpha=0,05$ ). Factor Loading merupakan korelasi antara indikator dengan variabel, jika lebih besar dari 0,5 dianggap validitasnya terpenuhi begitu juga jika nilai T-Statistic lebih besar dari 1,96 maka signifikansinya terpenuhi.

Berdasarkan pada tabel outer loading di atas, seluruh indikator reflektif pada variable Kepercayaan Konsumen (X1), Kualitas Produk (X2), Persepsi Harga (X3), dan Keputusan Pembelian (Y), menunjukan factor loading (original sample) lebih besar dari 0,50 dan atau signifikan (Nilai T-Statistic lebih dari nilai $\mathrm{Z} \alpha=0,05(5 \%)=1,96$ ), dengan demikian hasil estimasi seluruh indikator telah memenuhi Convergen vailidity atau validitasnya baik.

Pengukuran validitas indikator juga bisa dilihat dari tabel Cross Loading, apabila nilai loading faktor setiap indikator pada masing-masing variabel lebih besar dari 0,6 dan nilai loading faktornya lebih besar daripada loading faktor tiap indikator pada variabel lainnya maka loading faktor tersebut dikatakan valid, namun jika sebaliknya maka dikatakan tidak valid.

Tabel 10. Cross Loading

\begin{tabular}{|c|c|c||c|c|}
\hline INDIKATOR & $\begin{array}{c}\text { KEPERCAYAAN } \\
\text { KONSUMEN (X1) }\end{array}$ & $\begin{array}{c}\text { KEPUTUSAN } \\
\text { PEMBELIAN (Y) }\end{array}$ & $\begin{array}{c}\text { KUALITAS } \\
\text { PRODUK (X2) }\end{array}$ & $\begin{array}{c}\text { PERSEPSI } \\
\text { HARGA (X3) }\end{array}$ \\
\hline \hline $\mathrm{X} 1.1$ & 0.841436 & 0.475179 & 0.525868 & 0.608812 \\
\hline \hline $\mathrm{X} 1.2$ & 0.798054 & 0.449728 & 0.566725 & 0.609715 \\
\hline \hline $\mathrm{X} 1.3$ & 0.880249 & 0.555229 & 0.649309 & 0.602519 \\
\hline \hline $\mathrm{X} 2.1$ & 0.658243 & 0.559628 & 0.896345 & 0.527122 \\
\hline \hline $\mathrm{X} 2.2$ & 0.646656 & 0.481619 & 0.854709 & 0.593481 \\
\hline \hline $\mathrm{X} 2.3$ & 0.468020 & 0.449129 & 0.823577 & 0.326930 \\
\hline \hline $\mathrm{X} 3.1$ & 0.599955 & 0.387830 & 0.477691 & 0.804077 \\
\hline \hline $\mathrm{X} 3.3$ & 0.622064 & 0.562105 & 0.436158 & 0.882747 \\
\hline \hline $\mathrm{Y} 1$ & 0.558587 & 0.347677 & 0.521458 & 0.778551 \\
\hline \hline $\mathrm{Y} 2$ & 0.328229 & 0.745126 & 0.419139 & 0.347405 \\
\hline \hline $\mathrm{Y} 3$ & 0.567542 & 0.901972 & 0.519237 & 0.532331 \\
\hline \hline
\end{tabular}


Dari hasil olah data cross loading diperoleh seluruh nilai loading faktor (diarsir) pada masing-masing indikator baik pada variabel Kepercayaan Konsumen (X1), Kualitas Produk (X2), Persepsi Harga (X3), dan Keputusan Pembelian (Y), menunjukan nilai loading faktor diatas 0,6 dan lebih besar dibandingkan dengan loading faktor indikator dari variabel lainnya, sehingga dapat dikatakan seluruh indikator pada penelitian ini terpenuhi validitasnya atau validitasnya baik.

Tabel 11. Average Variance Extracted (AVE)

\begin{tabular}{|l|c|}
\hline & AVE \\
\hline KEPERCAYAAN KONSUMEN (X1) & 0.706581 \\
\hline KEPUTUSAN PEMBELIAN (Y) & 0.693947 \\
\hline KUALITAS PRODUK (X2) & 0.737414 \\
\hline \hline PERSEPSI HARGA (X3) & 0.677308 \\
\hline
\end{tabular}

Model Pengukuran berikutnya adalah nilai Avarage Variance Extracted (AVE), yaitu nilai menunjukkan besarnya varian indikator yang dikandung oleh variabel latennya. Konvergen Nilai AVE lebih besar 0,5 menunjukkan kecukupan validitas yang baik bagi variabel laten. Pada variabel indikator reflektif dapat dilihat dari nilai Avarage variance extracted (AVE) untuk setiap konstruk (variabel). Dipersyaratkan model yang baik apabila nilai AVE masing-masing konstruk lebih besar dari 0,5.

Hasil pengujian AVE untuk variabel Kepercayaan Konsumen (X1) sebesar 0.706581, variabel Kualitas Produk (X2) sebesar 0.737414, variabel Persepsi Harga (X3) sebesar 0.677308, dan Keputusan Pembelian (Y) sebesar 0.693947, keempat variabel tersebut menunjukkan nilai lebih dari 0,5 , jadi secara keseluruhan variabel dalam penelitian ini dapat dikatakan validitasnya baik.

Tabel 12. Composite Reliability

\begin{tabular}{|l|c|}
\hline & Composite Reliability \\
\hline KEPERCAYAAN KONSUMEN (X1) & 0.878238 \\
\hline KEPUTUSAN PEMBELIAN (Y) & 0.871152 \\
\hline KUALITAS PRODUK (X2) & 0.893783 \\
\hline PERSEPSI HARGA (X3) & 0.862609 \\
\hline
\end{tabular}

Reliabilitas konstruk yang diukur dengan nilai composite reliability, konstruk reliabel jika nilai composite reliability di atas 0,70 maka indikator disebut konsisten dalam mengukur variabel latennya.

Hasil pengujian Composite Reliability menunjukkan bahwa variabel variabel Kepercayaan Konsumen (X1) sebesar 0.878238, variabel Kualitas Produk (X2) sebesar 0.893783, variabel Persepsi Harga (X3) sebesar 0.862609, dan Keputusan Pembelian (Y) sebesar 0.871152, keempat variabel tersebut menunjukkan nilai Composite Reliability diatas 0,70 sehingga dapat dikatakan seluruh variabel pada penelitian ini reliabel. 
Tabel 13. Latent Variable Correlations

\begin{tabular}{|l||c|c||c||c|}
\hline \hline & $\begin{array}{c}\text { KEPERCAYAAN } \\
\text { KONSUMEN (X1) }\end{array}$ & $\begin{array}{c}\text { KEPUTUSAN } \\
\text { PEMBELIAN (Y) }\end{array}$ & $\begin{array}{c}\text { KUALITAS } \\
\text { PRODUK (X2) }\end{array}$ & $\begin{array}{c}\text { PERSEPSI } \\
\text { HARGA } \\
\text { (X3) }\end{array}$ \\
\hline $\begin{array}{l}\text { KEPERCAYAAN } \\
\text { KONSUMEN (X1) }\end{array}$ & 1.000000 & & & \\
\hline $\begin{array}{l}\text { KEPUTUSAN } \\
\text { PEMBELIAN (Y) }\end{array}$ & 0.590254 & 1.000000 & & \\
\hline $\begin{array}{l}\text { KUALITAS } \\
\text { PRODUK (X2) }\end{array}$ & 0.693614 & 0.782047 & 1.000000 & \\
\hline $\begin{array}{l}\text { PERSEPSI HARGA } \\
\text { (X3) }\end{array}$ & 0.719881 & 0.544395 & 0.567084 & 1.000000 \\
\hline
\end{tabular}

Didalam PLS hubungan variabel atau konstruk satu dengan yang lain bisa saling berkorelasi satu dengan yang lain, baik itu variabel eksogen dengan endogen, atau variabel eksogen dengan eksogen seperti tampak pada tabel latent variabel correlations diatas. 7emakin mendekati nilai 1 maka memiliki korelasi semakin baik.

Dari tabel latent variabel correlations diatas diperoleh nilai korelasi rata-rata antar variabel satu dengan lainnya menunjukan nilai korelasi yang cukup tinggi dan bervariasi. Nilai korelasi tertinggi terdapat antara variabel Kualitas Produk (X2) dengan Keputusan Pembelian (Y) sebesar 0.782047, hal ini juga bisa dinyatakan bahwa diantara variabel yang ada didalam model penelitian, hubungan antara variabel Kualitas Produk (X2) dengan Keputusan Pembelian (Y) menunjukan hubungan yang lebih kuat daripada hubungan antara variabel lainnya, hal ini juga bisa diinterpretasikan bahwa dalam model penelitian ini tinggi rendahnya Keputusan Pembelian lebih banyak dipengaruhi oleh variabel Kualitas Produk dibandingkan variabel Kepercayaan Konsumen dan Persepsi Harga.

\section{2) Inner Model (Pengujian Modal Strktural)}

Pengujian terhadap model struktural dilakukan dengan melihat nilai R-Square yang merupakan uji goodness-fit model. Pengujian inner model dapat dilihat dari nilai R-square pada persamaan antar variabel latent. Nilai $\mathrm{R}^{2}$ menjelaskan seberapa besar variabel eksogen (independen/bebas) pada model mampu menerangkan variabel endogen (dependen/terikat) 0

Tabel 14. R-square

\begin{tabular}{|l||l|}
\hline & R Square \\
\hline KEPERCAYAAN KONSUMEN (X1) & \\
\hline KEPUTUSAN PEMBELIAN (Y) & 0.425707 \\
\hline KUALITAS PRODUK (X2) & \\
\hline PERSEPSI HARGA $(\mathrm{X} 3)$ & \\
\hline \hline
\end{tabular}

Nilai $\mathrm{R}^{2}=0.425707$. Hal ini dapat diinterpretasikan bahwa model mampu menjelaskan fenomena Keputusan Pembelian yang dipengaruhi oleh variabel bebas antara lain Kepercayaan 
Konsumen, Kualitas Produk dan Persepsi Harga dengan varian sebesar 42,57\%. Sedangkan sisannya sebesar $57,43 \%$ dijelaskan oleh variabel lain diluar penelitian ini (selain Kepercayaan Konsumen, Kualitas Produk dan Persepsi Harga).

Selain diketahui nilai $\mathrm{R}^{2}$, Goodness of Fit Model penelitian bisa diketahui dari besarnya $\mathrm{Q}^{2}$ atau $Q$-Square predictive relevance untuk model struktural, yaitu untuk mengukur seberapa baik nilai observasi yang dihasilkan oleh model dan juga estimasi parameternya. Nilai $Q$-square $>0$ menunjukkan model memiliki predictive relevance; sebaliknya jika nilai $Q$-Square $\leq 0$ menunjukkan model kurang memiliki predictive relevance. Perhitungan $Q$-Square dilakukan dengan rumus:

$Q 2=1-\left(1-R_{1}{ }^{2}\right)\left(1-R_{2}{ }^{2}\right) \ldots\left(1-R_{p}{ }^{2}\right)$ dimana $\mathrm{R}_{1}{ }^{2}, \mathrm{R}_{2}{ }^{2} \ldots \mathrm{R}_{\mathrm{p}}{ }^{2}$ adalah $R$-square variabel endogen dalam model persamaan. Besaran $\mathrm{Q}^{2}$ memiliki nilai dengan rentang $0<\mathrm{Q}^{2}$ $<1$, dimana semakin mendekati 1 berarti model semakin baik. Besaran $\mathrm{Q}^{2}$ ini setara dengan koefisien determinasi total pada analisis jalur (path analysis).

Pada penelitian ini besarnya nilai $\mathrm{Q}^{2}$ yaitu sebesar :

$$
\mathrm{Q}^{2}=1-(1-0.425707)=0.425707 \text {. }
$$

Dari hasil perhitungan $\mathrm{Q}^{2}$ dengan hasil 0.425707 , maka dapat disimpulkan model penelitian dapat dikatakan memenuhi predictive relevance.

\section{Pengujian Hipotesis}

Selanjutnya untuk pengujian hipotesis dapat dilihat hasil koefisien dan nilai T-statistic dari inner model pada tabel berikut ini.

Tabel 15. Path Coefficients (Mean, STDEV, T-Values)

\begin{tabular}{|l||c||c|c||c|c|}
\hline & $\begin{array}{c}\text { Path } \\
\text { Coefficients } \\
(\mathrm{O})\end{array}$ & $\begin{array}{c}\text { Sample } \\
\text { Mean (M) }\end{array}$ & $\begin{array}{c}\text { Standard } \\
\text { Deviation } \\
(\text { STDEV })\end{array}$ & $\begin{array}{c}\text { Standard } \\
\text { Error } \\
(\text { STERR })\end{array}$ & $\begin{array}{c}\text { T Statistics } \\
(\mid \mathrm{O} / \text { STERR })\end{array}$ \\
\hline $\begin{array}{l}\text { KEPERCAYAAN } \\
\text { KONSUMEN (X1) -> } \\
\text { KEPUTUSAN } \\
\text { PEMBELIAN (Y) }\end{array}$ & 0.230497 & 0.220397 & 0.112537 & 0.112537 & 2.048186 \\
\hline $\begin{array}{l}\text { KUALITAS PRODUK } \\
\text { (X2) -> KEPUTUSAN } \\
\text { PEMBELIAN (Y) }\end{array}$ & 0.305933 & 0.305721 & 0.080707 & 0.080707 & 3.790647 \\
\hline $\begin{array}{l}\text { PERSEPSI HARGA (X3) } \\
\text {-> KEPUTUSAN } \\
\text { PEMBELIAN (Y) }\end{array}$ & 0.204976 & 0.223298 & 0.091060 & 0.091060 & 2.250990 \\
\hline
\end{tabular}

Dari tabel diatas dapat diperoleh kesimpulan bahwa hipotesis yang menyatakan :

H1. Kepercayaan Konsumen (X1) berpengaruh positip terhadap Keputusan Pembelian (Y) dapat diterima, dengan path coefficients sebesar 0.230497 , dan nilai T-statistic sebesar $2.048186>1,96$ (nilai $\mathrm{T}$-tabel dari $\mathrm{Z} \alpha=0,05$ ), maka Signifikan (positif).

H2. Kualitas Produk (X2) berpengaruh positip terhadap Keputusan Pembelian (Y) dapat diterima, dengan path coefficients sebesar 0.305933 , dan nilai T-statistic 
sebesar $3.790647>1,96$ (nilai T-tabel dari $\mathrm{Z} \alpha=0,05$ ), maka Signifikan (positif).

H3. Persepsi Harga (X3) berpengaruh positip terhadap Keputusan Pembelian (Y) dapat diterima, dengan path coefficients sebesar 0.204976, dan nilai T-statistic sebesar $2.250990>1,96$ (nilai T-tabel dari $\mathrm{Z} \alpha=0,05$ ), maka Signifikan (positif).

Sebagaimana signifikansi hasil nilai T-Statistic dapat dilihat dari output smartPLS dengan bootstraping pada gambar sebagai berikut :

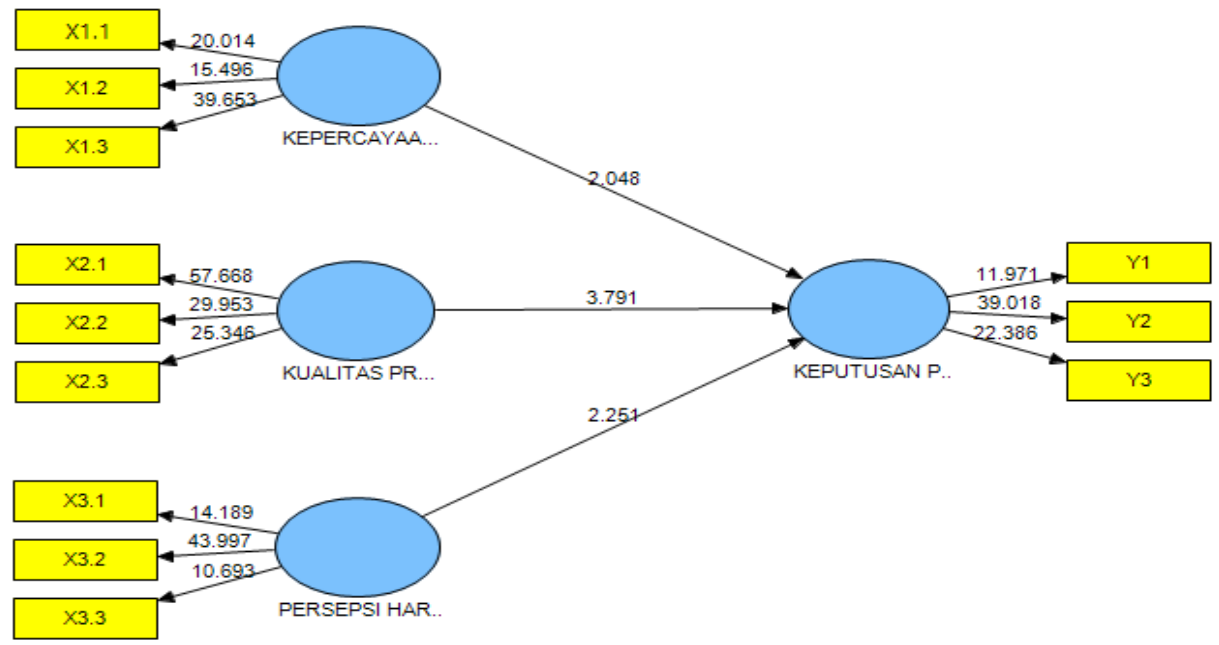

Gambar 1. Inner Model dengan nilai signifikansi T-Statistic Bootstraping Sumber : olah data, output smartPLS

\subsection{Pembahasan}

\section{Pengaruh Kepercayaan Konsumen terhadap Keputusan Pembelian}

Hasil penelitian ini menunjukkan bahwa kepercayaan konsumen berpengaruh positif terhadap keputusan pembelian. Kepercayaan konsumen diartikan sebagai pandangan yang didasari pada sudut pandang konsumen berdasarkan pengalaman, atau lebih pada urut-urutan transaksi atau interksi yang dicirikan oleh terpenuhinya harapan akan kinerja produk dan kepuasan. Secara umum, kepercayaan konsumen adalah tiang dari bisnis, dimana membangun dan menciptakan konsumen merupakan salah satu faktor yang paling penting bagi keberhasilan penjualan suatu produk, sehingga kepercayaan konsumen membuktikkan bahwa produk tersebut layak untuk dipasarkan.

Hasil Penelitian dari Istiqomah, Zainul Hidayat, Ainun Jariah (2019), menyatakkan bahwa kepercayaan konsumen berpengaruh positif terhadap keputusan pembelian. Hasil Wahyu Setia Dewi, Leonardo Budi Hasiolan, Maria M Minarsih (2016), menyatakkan bahwa Kepercayaan konsumen berpengaruh positif signifikan terhadap keputusan pembelian. Hasil penelitian ini didukung oleh kedua penelitian di atas, yaitu kepercayaan konsumen memberikkan dampak positif yang signifikan terhadap keputusan pembelian. Hal ini berarti bahwa semakin baik kepercayaan konsumen, maka semakin tinggi kecenderungan konsumen dalam melakukkan keputusan pembelian. 


\section{Pengaruh Kualitas Produk terhadap Keputusan Pembelian}

Hasil penelitian ini menunjukkan bahwa kualitas produk berpengaruh positif terhadap keputusan pembelian. Dimana kualitas produk memiliki pengaruh terhadap keputusan pembelian. Kualitas produk merupakkan salah satu alat yang digunakkan oleh para pemasar untuk menentukkan positioning produknya di pasar. Setiap perusahaan harus memilih tingkat kualitas produk yang dihaasilkannya sehingga akan membantu ataumenunjang usaha untuk meningkatkan atau mempertahankan positioning produk itu dalam pasar sasarannya.

Apabila kualitas produk yang ditawarkan dapat memenuhi keinginan dan kebutuhan konsumen maka produk tersebut akan mempengaruhi keputusan pembeliannya. Produk yang diterima oleh para konsumen adalah produk yang kualitasnya dapat memuaskan para konsumen, kualitas produk sangat berpengaruh untuk meyakinkan para konsumen melakukkan keputusan pembelian. Salah satu tujuan pelaksanaan kualitas produk adalah untuk mempengaruhi konsumen dalam menentukkan pilihannya untuk menggunakkan produk buatannya sehingga memudahkan konsumen dalam pengambilan keputusan pembelian.

Hasil penelitian dari Agnes Ligia Pratistia Walukow, Lisbeth Mananeke, dan Jantje Sepang (2014), menyatakan bahwa kualitas produk berpengaruh positif terhadap keputusan pembelian. Hasil penelitian Wahyu Setia Dewi, Leonardo Budi Hasiolan, Maria M Minarsih (2016) menyatakan bahwa kualitas produk berpengaruh positif signifikan terhadap keputusan pembelian. Hal ini berarti semakin baik kualitas pada produk yang ditawarkan Flaminggo Collection dalam memasarkan sebuah produknya, semakin besar kecenderungan yang dimiliki konsumen untuk melakukkan keputusan pembelian.

\section{Pengaruh Persepsi Harga terhadap Keputusan Pembelian}

Hasil penelitian ini menunjukkan bahwa persepsi harga bepengaruh positif terhadap keputusan pembelian. Persepsi harga diartikan sebagai suatu proses dimana seorang menyeleksi, mengorganisasikan, menginterpretasikan stimulus dalam suatu gambaran yang berarti menyeluruh. Secara umum, persepsi harga adalah salah satu pertimbangan penting dalam proses keputusan pembelian, dan kebanyakan konsumen mengevaluasi nilai (kombinasi antara harga dengan kualitas dan manfaat produk) dalam keputusan pembelian.

Tidak selamanya harga yang murah akan mencerminkan tingkat kualitas produk yang buruk. Begitu juga sebaliknya, harga yang mahal tidak selalu mencerminkan kualitas yang baik pula. Penilaian terhadap harga suatu produk dikatakan mahal, murah, atau biasa saja dari setiap konsumen tidak harus selalu sama. Hal ini tergantung dari persepsi harga konsumen yang dilator belakangi oleh lingkungan dan kondisi dari tiap konsumen itu sendiri. Sebagian besar konsumen akan mempersepsikan harga suatu produk dengan baik apabila harga yang ditetapkan perusahaan dirasa sesuai dengan kualitas dan manfaat produk yang didapatkan konsumen agar persepsi harga yang dibentuk oleh tiap individu diharapkan dapat mempengaruhi konsumen dalam menentukan keputusan pembelian. Hal ini berarti bahwa semakin baik persepsi harga yang sesuai dengan manfaat sebuah produk, maka semakin tinggi kecenderungan konsumen dalam melakukkan keputusan pembelian.

\section{KESIMPULAN}

Berdasarkan hasil penelitian dan pembahasan, maka dapat diambil beberapa kesimpulan sebagai berikut:

1) Kepercayaan Konsumen dapat menjadi peran penting terhadap Keputusan Pembelian pada Flaminggo Collection. Semakin tinggi kepercayaan konsumen maka semakin tinggi pula keputusan pembelian pada toko baju tersebut. 
2) Kualitas Produk dapat memberikan peran penting pada Flaminggo Collection. Semakin tinggi kualitas produk maka semakin tinggi pula keputusan pembelian pada toko baju tersebut.

3) Persepsi Harga dapat memberikan peran penting terhadap keputusan pembelian pada Flaminggo Collection. Semakin tinggi persepsi harga maka semakin tinggi pula keputusan pembelian pada toko baju tersebut.

\section{Saran}

Dapat dikemukakan beberapa saran yang diharap dapat bermanfaat sebagai berikut:

1) Kualitas produk yang ditawarkan oleh Flaminggo Collection mempunyai kualitas yang sangat baik di bandingkan toko baju lainnya, dimana Flaminggo Collection harus bias mempertahankan kualitas pada produk yang sudah dimiliki sehingga konsumen tidak beralih ke produk di toko baju lainnya.

2) Dengan lebih memperhatikkan persepsi harga melalui indikator kesesuaian harga dengan manfaat produk. Flaminggo Collection dapat menetapkan harga beli baju yang sesuai dengan manfaat produk yang didapatkan konsumen dan sesuai dengan keinginan dan harapan konsumen dalam memilih produk baju tersebut. Sehingga diharapkan dapat mendorong jumlah pembelian baju di masa yang akan datang.

3) Flaminggo Collection harus mempertahankan dan tetap memperhatikan kepercayaan konsumennya. Dikarenakan kepercayaan konsumen memiliki pengaruh terhadap keputusan pembelian. Konsumen yang percaya akan suatu produk yang dijualkan oleh Flaminggo Collection maka akan cenderung melakukan keputusan untuk membeli produk tersebut.

\section{DAFTAR PUSTAKA}

Dewi, Wahyu Setia L. B. (2016). Pengaruh Kualitas Produk, Kepercayaan Terhadap Keputusan Pembelian Dengan Kepuasan Konsumen Sebagai Variabel Intervening. Journal Of Management, 2.

Gerung, Christy Jacklin J. S. (2017). Pengaruh Kualitas Produk, Harga dan Promosi terhadap Keputusan Pembelian mobil nissan X-trail pada PT. Wahana Wirawan Manado. Jurnal $E M B A, 2221$.

Ishak, A. (2011). Manajemen Operasi. Yogyakarta: Graha Ilmu.

Istiqomah, Z. H. (2019). Analisis Pengaruh Kepercayaan, Iklan dan Persepsi Resiko terhadap Keputusan Pembelian di Situs Shopee di Kota Lumajang. Progress Coference ,557.

Laurensia, J. (2016, Februari 26). Mengapa Fashion Itu Penting? Dipetik Februari 26,2021, dari kompasiana:

https://www.kompasiana.com/jesicalaurensia/56d04cdc717a6126165faf9b/mengapafashion-itu-penting

Maris, s. (2020, Maret 6). Persaingan Semakin Ketat, Ini Kiat Jitu Kembangkan Bisnis UMKM. Dipetik Februari 26, 2021, dari today.line.me: https://today.line.me/id/v2/article/Persaingan+Semakin+Ketat+Ini+Kiat+Jitu+Kembang k $\underline{\text { a }+ \text { Bisnis+UMKM-zoYY15 }}$ 
Melalui Situs Web: Tinjauan Kritis Pengetahuan Yang Masih Ada. Jurnal dari Akademi Ilmu Pemasaran. Vol. 30, No. 4, hlm.362-375.

Philip Kotler, K. L. (2007). Manajemen Pemasaran Jilid 1, Edisi kedua belas. Jakarta: PT. Indeks. Philip Kotler, K. L. (2009). Manajemen Pemasaran Jilid 2 Edisi 13. Dalam K.

L. Philip Kotler, Manajemen Pemasaran Jilid 2 Edisi 13 (hal. 179). Jakarta: Erlangga.

Rangkuti, F. (2001). RISET PEMASARAN. Jakarta: PT. GRAMEDIA PUSTAKAUTAMA.

Riduwan (2010). Skala Pengukuran Variabel-Variabel Penelitian. Bandung: AlfabetaSantoso, I. (2016). Peran Kualitas Produk dan Layanan, Harga dan Atmosfer Rumah Makan Cepat Saji terhadap Keputusan Pembelian dan Kepuasan Konsumen. Jurnal Manajemen Teknologi, 94.

Sugiyono. 2010. Metode Penelitian Pendidikan Pendekatan Kuantitatif, kualitatif, dan R\&D. Bandung: Alfabeta

Sugiyono. 2008. Metode Penelitian Kuantitatif Kualitatif dan R\&D. Bandung : ALFABETA

Walukow, Agnes Ligia Pratistia L. M. (2014). Pengaruh Kualitas Produk, Harga, Promosi dan Lokasi terhadap Keputusan Pembelian Konsumen di Bentenan Center Sonder Minahasa. Jurnal EMBA, 1737.

Wariki, Grace Marleen L. M. (2015). Pengaruh Bauran Promosi, Persepsi Harga Dan Lokasi Terhadap Keputusan Pembelian Dan Kepuasan Konsumen Pada Perumahan Tamansari Metropolitan Manado. Jurnal EMBA, 1073.

Zeithaml, V.A., Parasuraman, A. dan Malhotra, A. 2002. Service Quality Deliver 